\title{
Upper-mantle deformation beneath the Pyrenean domain inferred from $S K S$ splitting in northern Spain and southern France
}

\author{
Mickaël Bonnin, ${ }^{1}$ Sébastien Chevrot, ${ }^{2}$ Ianis Gaudot, ${ }^{1}$ Méric Haugmard ${ }^{1}$ \\ and the PYROPE working group \\ ${ }^{1}$ Laboratoire de planétologie et de géodynamique, CNRS, université de Nantes, Nantes, France.E-mail: mickael.bonnin@univ-nantes.fr \\ ${ }^{2}$ Géosciences environnement Toulouse, CNRS, université Paul Sabatier, IRD, Toulouse, France
}

Accepted 2017 May 5. Received 2017 April 28; in original form 2016 December 22

\begin{abstract}
SUMMAR Y
We performed shear wave splitting analysis on 203 permanent (French RLPB, CEA and Catalonian networks) and temporary (PYROPE and IberArray experiments) broad-band stations around the Pyrenees. These measurements considerably enhance the spatial resolution and coverage of seismic anisotropy in that region. In particular, we characterize with different shear wave splitting analysis methods the small-scale variations of splitting parameters $\phi$ and $\delta t$ along three dense transects crossing the western and central Pyrenees with an interstation spacing of about $7 \mathrm{~km}$. While we find a relatively coherent seismic anisotropy pattern in the Pyrenean domain, we observe abrupt changes of splitting parameters in the Aquitaine Basin and delay times along the Pyrenees. We moreover observe coherent fast directions despite complex lithospheric structures in Iberia and the Massif Central. This suggests that two main sources of anisotropy are required to interpret seismic anisotropy in this region: (i) lithospheric fabrics in the Aquitaine Basin (probably frozen-in Hercynian anisotropy) and in the Pyrenees (early and late Pyrenean dynamics); (ii) asthenospheric mantle flow beneath the entire region (imprint of the western Mediterranean dynamics since the Oligocene).
\end{abstract}

Key words: Mantle processes; Europe; Body waves; Broad-band seismometers; Seismic anisotropy; Dynamics of lithosphere and mantle.

\section{INTRODUCTION}

The Pyrenees formed between the Aptian (120 Ma) and the Eocene (40 Ma) as a consequence of the convergent motion of Iberia relative to Eurasia. The first stage of formation of the Pyrenees is related to the opening of the North Atlantic oceanic domain during the Early Cretaceous. The position of Iberia at that time, in particular after the magnetic anomaly M0 (125 Ma), is nevertheless poorly constrained, the motion of Iberia - and notably the opening of the Bay of Biscay-occurred during the superchron 34 (from 125 to $85 \mathrm{Ma}$ ). Consequently, no magnetic anomaly can be used for kinematic reconstructions during that period. Three main kinematic reconstructions for the movement of Iberia have been proposed (see Barnett-Moore et al. 2016, and references therein for a review). In brief: (i) $300 \mathrm{~km}$ of left-lateral strike-slip motion (Le Pichon \& Sibuet 1971; Choukroune \& Mattauer 1978; Olivet 1996); (ii) the opening, between Iberia and Eurasia, of a 300-400 km wide oceanic basin that was later closed by the subduction of the Iberian lithosphere beneath Eurasia (Srivastava et al. 1990, 2000; Sibuet et al. 2004; Vissers \& Meijer 2012); (iii) a transtensional and extensional motion (Jammes et al. 2009). On the other hand, there is a consensus to start the initiation of the Pyrenean collision around $85 \mathrm{Ma}$. The continuation of the compression up to mid Eocene times (40 Ma) finally caused the uplift of the belt.

Different domains can be defined to describe the structure of the Pyrenees (Choukroune 1992, see Fig. 1a): (1) the Pyrenean Axial Zone (PAZ) represents the thickened Iberian crust composed of deformed Hercynian crystalline massifs (Vissers 1992), (2) the North Pyrenean Zone (NPZ) localized to the north of the North Pyrenean Fault (NPF) is the zone where the largest deformations are observed and corresponds to the remnants of the extended continental domain that lay between Iberia and Eurasia before the collision, and (3) the North Pyrenean Front Thrust (NPFT) and South Pyrenean Front Thrust (SPFT), which overthrust the Aquitaine and Ebro foreland basins, respectively.

Seismic anisotropy is mostly related to rock microfracturing and layering in the upper crust (e.g. Crampin 1984) or with latticepreferred orientation of anisotropic minerals at greater depth such as in the lower crust (Barruol \& Mainprice 1993), or in the upper mantle (e.g. Mainprice \& Silver 1993). Seismic anisotropy in the upper-mantle results primarily from elastic anisotropy of rockforming minerals - particularly olivine-which develop preferred orientations in response to tectonic stress and flow (e.g. Nicolas \& Christensen 1987; Mainprice et al. 2000). Seismic anisotropy 

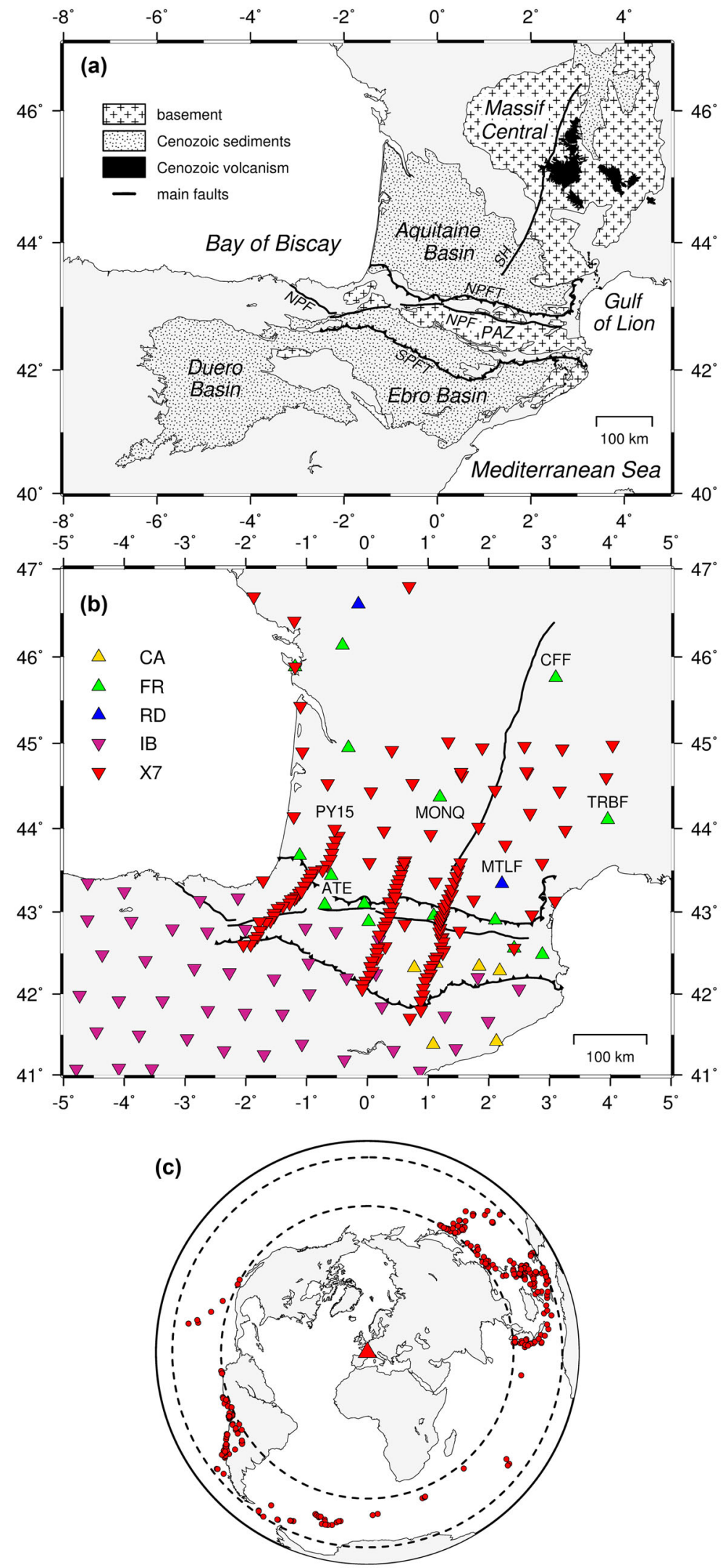

Figure 1. (a) Map presenting the main structural domains of the Pyrenees region. PAZ: Pyrenean Axial Zone; NPF: North Pyrenean Fault; NPFT: North Pyrenean Frontal Thrust; SH: Sillon Houillier; SPFT: South Pyrenean Frontal Thrust. (b) Localization map of the 203 broad-band stations analysed in this study with the names of the stations cited in the text. (c) Backazimuthal coverage obtained for $S K S$-waves at the FR.CFF station (Clermont-Ferrand, France). Red circles represent earthquakes with $M_{\mathrm{W}}>6.0$ that occurred at epicentral distances ranged between 90 and $120^{\circ}$ between 11/2011 and 06/2015. 
is thus a powerful tool for mapping upper-mantle deformation and for studying the dynamics of the lithosphere/asthenosphere system. Shear wave splitting is a direct manifestation of birefringence: when a shear wave propagates through an anisotropic medium it splits into two orthogonally polarized quasi-shear waves with different velocities. Two parameters can be measured to quantify the birefringence of shear waves (generally from records of core-refracted shear waves such as $S K S$ ): (1) the delay $(\delta t)$ between the two split quasi-shear waves that depends both on the thickness and on the intrinsic anisotropy of the medium and (2) the orientation of the polarization plane of the faster shear wave $(\phi)$, which is related to the orientation of the pervasive fabric in the anisotropic structure (foliation and lineation) or to fluid-filled microcracks at upper crustal levels.

Previous analyses of $S K S$ splitting in the Pyrenean domain revealed relatively homogeneous $\mathrm{N} 100^{\circ} \mathrm{E}$ fast polarization directions (Barruol \& Souriau 1995; Barruol et al. 1998), that is, close to parallel to the strike of the belt. They were interpreted as resulting from the strike-slip deformation associated with the rotation of Iberia and/or to the pure shear deformation caused by the N/S collision between Iberia and Europe. Anisotropy was thus mostly believed to be localized within the lithosphere. More recently Díaz et al. (2015), using data from the Topo-Iberia deployment, showed that those $\mathrm{N} 100^{\circ} \mathrm{E}$ fast azimuths are observed throughout the Iberian peninsula and Barruol et al. $(2004,2011)$ found an anti-clockwise rotation of the directions of anisotropy from close to $\mathrm{N} 150^{\circ} \mathrm{E}$ in the northern French Massif Central to close to E/W directions along the Mediterranean coast. Díaz et al. (2015) interpreted their observations by a global NE directed asthenospheric flow while Barruol et al. $(2004,2011)$ by mantle flow caused by the Tyrrhenian slab retreat toward the E-SE since the Oligocene $(\sim 35 \mathrm{Ma})$. The dense data set now available in the region, which covers the entire belt and - for the first time - its northern foreland, offers a new opportunity to investigate the lateral variations of splitting parameters along and across the Pyrenean belt and to extend our maps of seismic anisotropy toward the northwestern edge of the Mediterranean basin.

After a presentation of the data and methods used in this work, we describe the individual and, more specifically, the average splitting parameters pattern observed. We then propose geodynamic interpretations of the observed anisotropy in that region.

\section{DATA AND METHOD}

We analysed an extensive data set of 203 broad-band stations with an overall spacing of about $60 \mathrm{~km}$ (Fig. 1b).

We used 131 temporary stations from the PYROPE deployment (X7 code). Among this network, stations PW01 to PW28 and PC01 to PC26 form the western and central transect, respectively, while PE01 to PE22 and PF01 to PF15 form the southern and northern eastern transect, respectively (see Supporting Information Fig. S1 for the detail of the transects). PY01 to PY96 stations form the PYOPE backbone. We also used 47 temporary stations from the northern leg of the IberArray experiment (IB code). The station coverage is further enhanced by 16 stations of the French permanent broad-band network (FR code), 2 stations from the CEA permanent network (RD code) and 7 stations from the Catalonian permanent network (CA code, Xarxa Sísmica de Catalunya). In the central and western Pyrenees, station spacing is locally reduced to about $7 \mathrm{~km}$ along three dense transects.

To observe distinct $S K S$ phases with high signal-to-noise ratio (SNR hereafter), we systematically select events with magnitude
$\left(M_{\mathrm{W}}\right)$ larger than 6.0 occurring at epicentral distances between $90^{\circ}$ and $120^{\circ}$. At each station, we inspected between 30 and 350 events fitting our criteria, depending on their recording duration (from 1 to $7 \mathrm{yr}$ ). Event origin times and locations were taken from the CMT catalogue (Dziewoński \& Anderson 1981; Ekström et al. 2012). The theoretical arrival times of $S K S$ phase were computed in the IASP91 Earth reference model (Kennett \& Engdahl 1991). Supporting Information Table S1 summarizes the deployment periods (or selected time-range for permanent stations), the number of requested events and the number of measurements performed at each station.

Shear wave splitting is known to be extremely sensitive to the SNR (e.g. Restivo \& Helffrich 1999; Monteiller \& Chevrot 2010), and the data selection procedure thus cannot be easily automatized. We thus use a semi-automatic scheme that allows us to carefully look at seismograms, discard noisy signals, choose the appropriate analysis window and filter the records to optimize the SNR (zerophase 2-poles Butterworth filters with various combinations of corner frequencies - typically between 0.01 and $0.4 \mathrm{~Hz}$ ). This procedure has been implemented with the SplitLab software (Wüstefeld et al. 2008, http://splitting.gm.univ-montp2.fr).

For each selected event we measure the splitting parameters, that is, the azimuth of the fast shear wave polarization $(\phi)$ and the delay time $(\delta t)$ between the fast and slow quasi-shear waves. We use two of the single-event analysis techniques available in SplitLab: rotation/correlation (Bowman \& Ando 1987), and minimum energy (Silver \& Chan 1991, SC hereafter). Using different singleevent analysis techniques is useful for checking the reliability of the measurements (Wüstefeld \& Bokelmann 2007) and for assigning a quality factor to each measurement. The rotation/correlation is used only for quality check and the results obtained with this method will not be further discussed. The assigned quality depends on several parameters: (1) the SNR of the initial waveform, (2) the correlation between the fast and slow quasi-shear waves, (3) the linear pattern of particle motion in the horizontal plane after correction, (4) the size of the 95 per cent confidence region and (5) the similarity between the results obtained with the different analysis methods. 'Good' measurements - such as the one shown in Fig. 2-satisfy the following conditions: high SNR, good correlation between fast and slow quasi-shear waves, linear particle motion, small confidence region and good correlation between the results coming from the two analysis methods. The $S K S$ record shown in Fig. 2 has a strong energy on the transverse component $(\mathrm{T})$, and the elliptical particle motion in the T-Q plane normal to the ray is close to linear after anisotropy correction. 'Fair' measurements meet at least four criteria; the other ones are 'poor' measurements.

In addition to these measurements, we observe 'nulls', that is, event-station pairs devoid of energy on the transverse component, suggesting that the $S K S$-wave has not been split. This may happen in four different cases (e.g. Savage 1999): (1) the medium is isotropic (or close to), (2) the fast axis is vertical, (3) the existence of two anisotropic layers with orthogonal symmetry axes and with similar delay times, (4) the incoming wave is polarized parallel to the slow or fast polarization direction. The first three cases will lead to null measurements at all the azimuths and cannot be distinguished from shear wave splitting observations alone. We also ascribe quality to these measurements using different criteria: the presence of energy on the transverse component, the SNR, and the linearity of the particle motion. 'Good' nulls are characterized by high SNR on the radial component and no energy on the transverse component (see Fig. 3); 'fair' measurements correspond to cases where the transverse component amplitude is insufficient to measure splitting. 'Nulls' measurements are generally discarded in studies that use single-event analysis methods as they do not contribute to the 

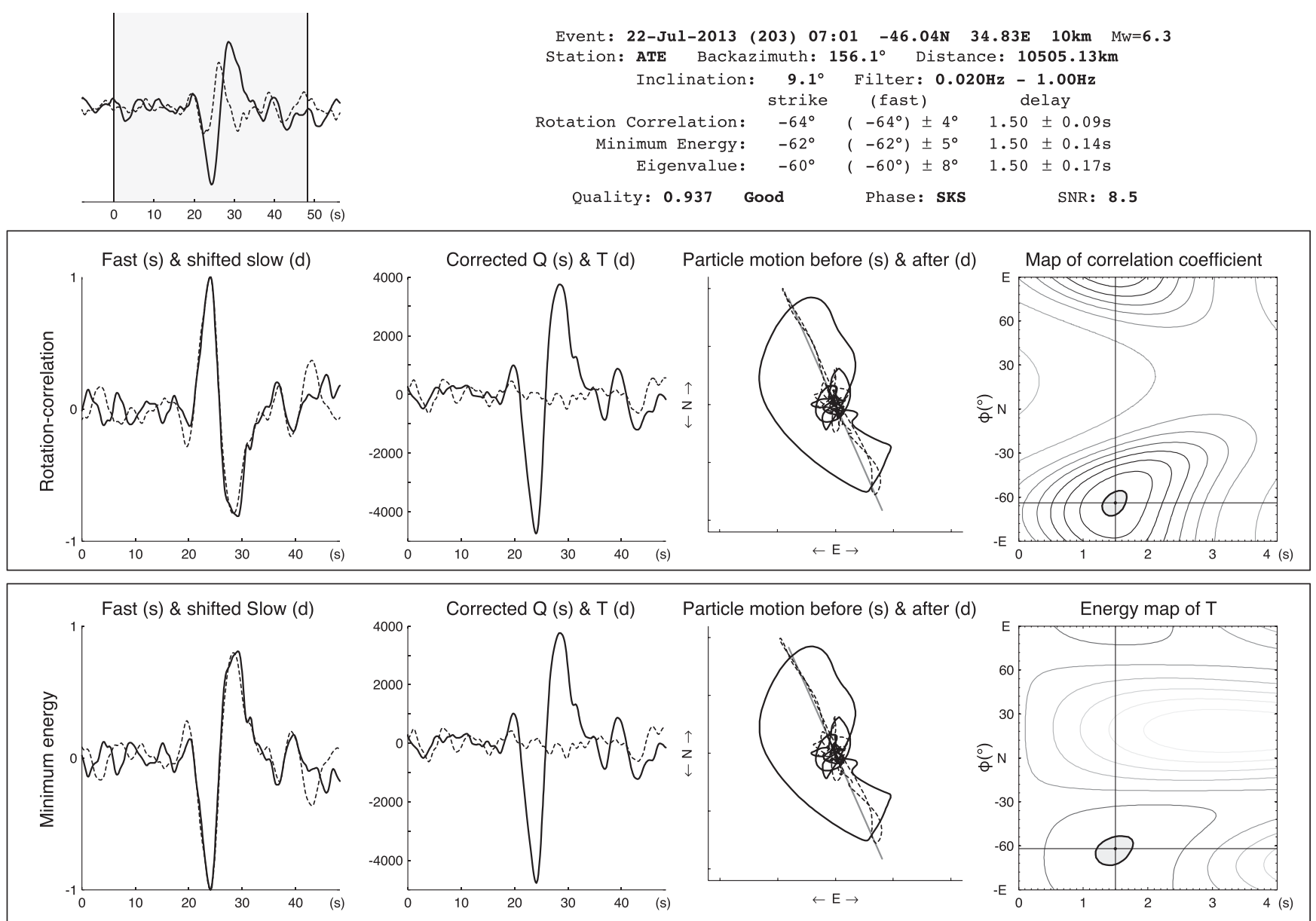

Figure 2. Example of a 'good' splitting measurement. Top left: radial (solid) and transverse (dashed) components of the seismogram of the event of the 22nd of July 2013 recorded at station FR.ATE. Shaded zone represents the analysis window. Top right: Information on the event used and on the results obtained from the different analysis methods. Middle: diagnostic windows for the rotation-correlation method (Bowman \& Ando 1987). Bottom: diagnostic windows for the Silver \& Chan (1991) method. From left to right: fast and shifted slow shear waves; corrected radial (Q) and transverse (T) components of the seismograms; particle motion before and after the anisotropy removal; error surfaces. 's' and 'd' mean solid and dashed, respectively.

arithmetical average of individual splitting measurements. However, they can provide useful constraints on the average $\phi$ and $\delta t$ at a particular station especially for temporary deployments for which good quality records of $S K S$-waves can be scarce. This motivated our choice to also consider the multi-event methods developed by Chevrot (2000, SI for Splitting Intensity hereafter) and Wolfe \& Silver (1998, WS hereafter) as they both take into account 'nulls' in their estimation of averaged splitting parameters.

The multichannel method (Chevrot 2000; Chevrot et al. 2004) fits the backazimuthal dependence of splitting intensity with a sinusoid whose phase and amplitude give the mean $\phi$ and $\delta t$, respectively (see Fig. 4a). Splitting intensities are estimated only for the 'good' and 'fair' nulls and non-nulls measurements analysed with the single-event approaches and using the same analysis window and bandpass filters. For consistency, as advocated in Monteiller \& Chevrot (2010), we then stack the individual splitting intensities within $10^{\circ}$ backazimuthal bins and compute their average and standard deviation using a bootstrap algorithm (Efron \& Tibshirani 1991). The Wolfe \& Silver (1998) technique stacks the 'good' and 'fair' nulls and non-nulls individual transverse energy maps obtained from the SC analyses to find the global minimum that corresponds to the mean $\phi$ and $\delta t$ (see Fig. 4b). The individual energy maps are normalized by their minimum value prior to stacking in order to account for their respective SNR. Previous studies have shown that both approaches produce equivalent results (Long \& van der Hilst 2005; Monteiller \& Chevrot 2010), a result that is confirmed by our study (see Figs $4 \mathrm{c}-\mathrm{d}$ ). However, the splitting intensity requires at least three backazimuthal bins to be used, which may be problematic for temporary stations when the deployment is very short. In such situations WS is a good alternative to get robust estimates of $\phi$ and $\delta t$.

\section{RESULTS}

\subsection{Individual splitting measurements}

Fig. 5 summarizes our individual shear wave splitting measurements with the SC method. It shows that, at the regional scale, splitting parameters do not demonstrate clear evidence for widespread backazimuthal dependence, and thus do not a priori indicate the presence of regional scale vertical or lateral complexities in the anisotropic structures, such as layered anisotropy (Savage \& Silver 1993; Silver \& Savage 1994) or anisotropy with dipping axes of symmetry (Babuška et al. 1993; Š́lený \& Plomerová 1996). The 'good' measurements, in particular, globally point to relatively well defined directions and delay times. This is clearly observed on the stereographic projections of the 'good' and 'fair' splitting measurements 

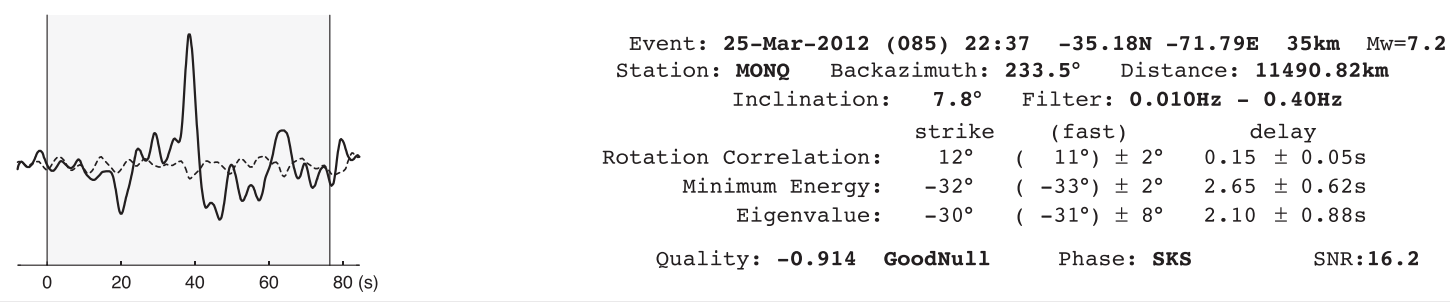

Quality: -0.914 GoodNull Phase: SkS SNR:16.2
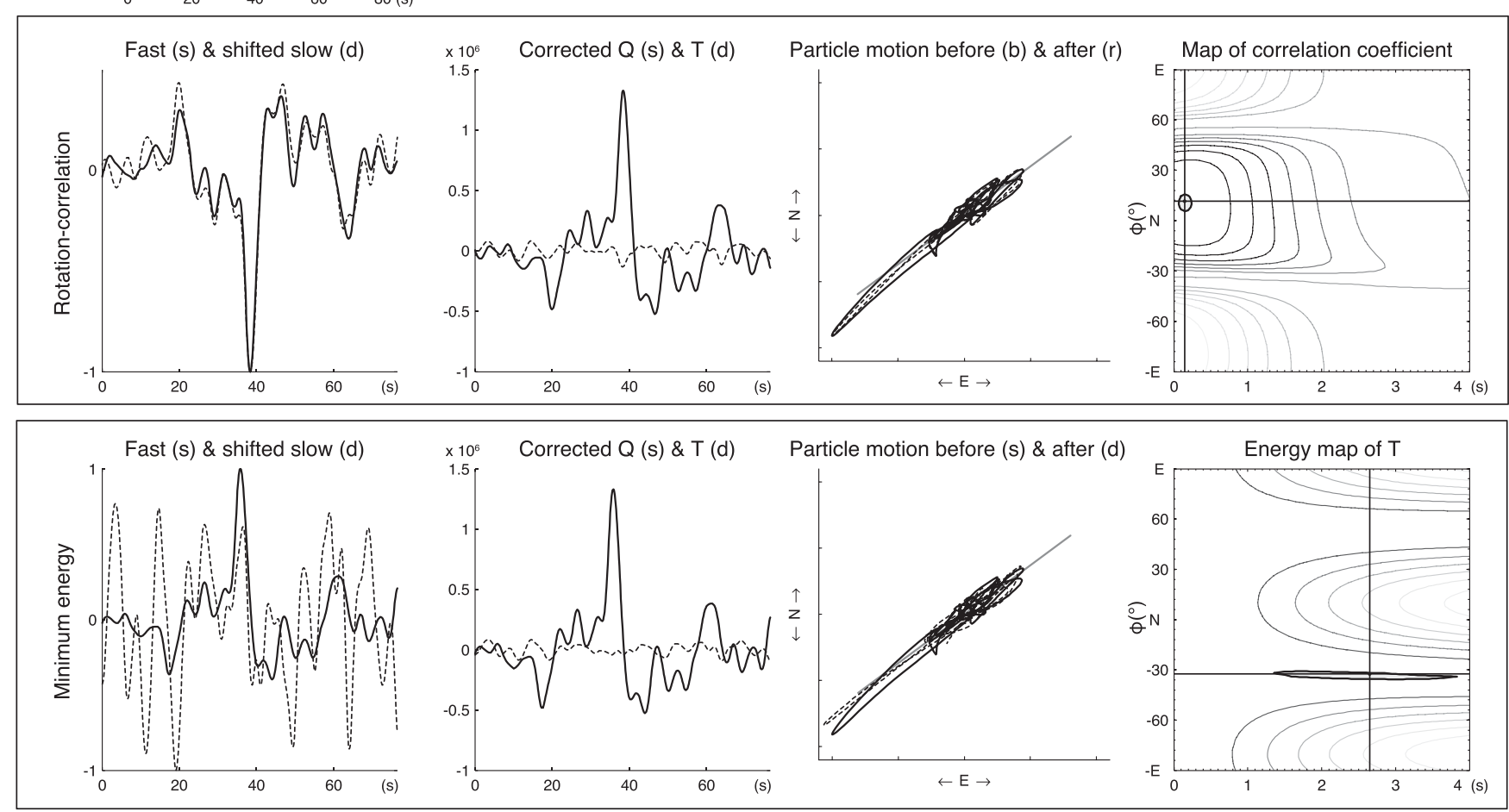

Figure 3. Example of a 'good' null for the event of the 25th of March 2012 recorded at station FR.MONQ. See Fig. 2 for the details of the different panels.

at each station (Supporting Information Fig. S1), which suggests that the occasional dispersion of measurements is mainly caused by the lower quality of the 'fair' measurements. Nevertheless, at a few stations such as TRBF (Supporting Information Fig. S1), measurements suggest some degree of azimuthal dependence. However there is no clear evidence for a $\pi / 2$ periodicity that would indicate the presence of layered anisotropy (Savage \& Silver 1993). On the other hand, we should point out that backazimuthal coverage is rather poor at most stations (Fig. 1c) and that complex 3D anisotropic structures would be hard to evidence with the currently available data, even if present. Note also that the large splitting delays $\delta t>2.5 \mathrm{~s}$ observed at some sites always correspond to measurements made with events whose backazimuth are close to the null directions - for which SC method is unstable. SI and WS approaches are however not penalized by these data. We obtained few robust splitting measurements at numerous stations of the PYROPE deployment, especially in the Aquitaine Basin and along the French Atlantic coast (solid circle on Fig. 5a).

Fig. 5(b) shows the backazimuthal distribution of events that lead to 'nulls' splitting measurements. A large majority of these directions are compatible with the splitting measurements shown above. Indeed, 'nulls' are generally observed when $S K S$-waves sample the fast or slow directions of anisotropy in the medium, causing 'nulls' directions parallel or perpendicular to the averaged $\phi$ directions. No station appears to generate 'nulls' for every incoming directions, which would indicate the presence of an isotropic mantle underneath the station. However, the sparse backazimuthal cover- age available in this region (see Fig. 1b) provides only few events in the northwestern and southeastern quadrants.

\subsection{Average splitting parameters}

Since we observe little evidence for a complex 3D distribution of anisotropy, from now on we will focus on the average, or apparent, values of splitting parameters. At most sites, and especially at the permanent stations, SI and WS techniques generally give similar results both in direction and amplitude, as can be seen in Fig. 6 . This is a clear indication of the robustness of the average splitting parameters at those sites, as the two methods are independent. An illustration is given on Figs 4(c)-(d) for which average splitting parameters for station ATE from SI (solid line) and WS (dashed line) are shown. Average splitting parameters at each station can be found in Supporting Information Table S2.

As previously evidenced by Díaz et al. (2015), $\phi$ directions are relatively homogeneous in Spain (thick black bars on Fig. 6), most stations showing fast directions close to $\mathrm{N} 100^{\circ} \mathrm{E}$ (Fig. 7a). In contrast, the splitting delays are less homogeneous (Fig. 7b): relatively high ( $>1.2 \mathrm{~s}$ ) delays are observed along the Mediterranean coast, while average values between 0.6 and $1.0 \mathrm{~s}$ are observed everywhere else.

The Pyrenean domain (between the SPFT and the NPFT) is also characterized by relatively homogeneous $\mathrm{N} 100^{\circ} \mathrm{E}$ fast directions. This pattern (blue bars on Fig. 6) previously recognized in Barruol et al. (1998) is also clearly expressed in the three dense transects 


$$
\text { SI: } \phi=-74^{\circ} ; \delta \mathrm{t}=0.9 \mathrm{~s}
$$

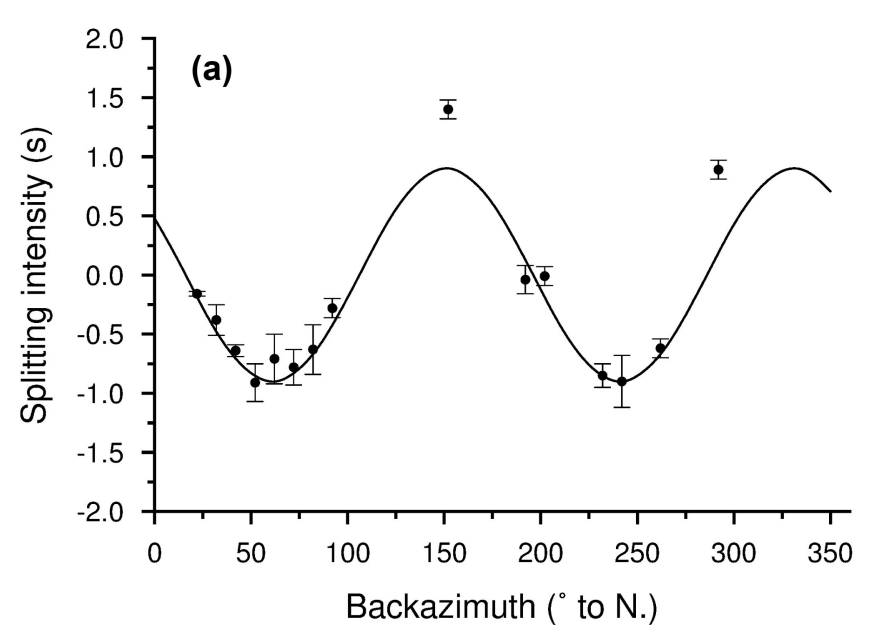

WS: $\phi=-78^{\circ} ; \delta \mathrm{t}=0.9 \mathrm{~s}$

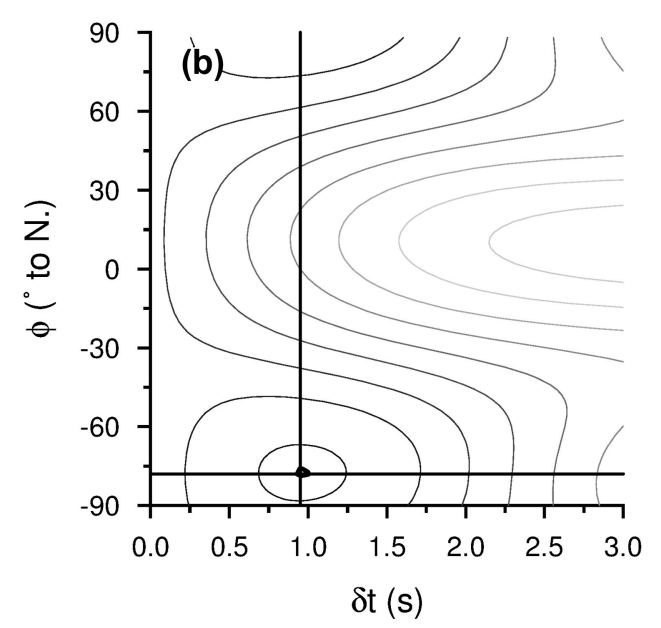

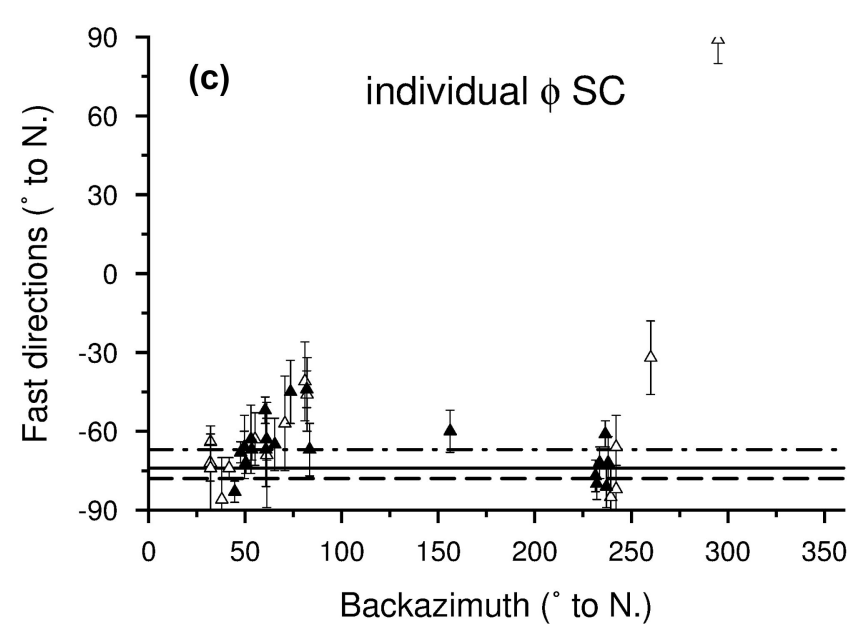

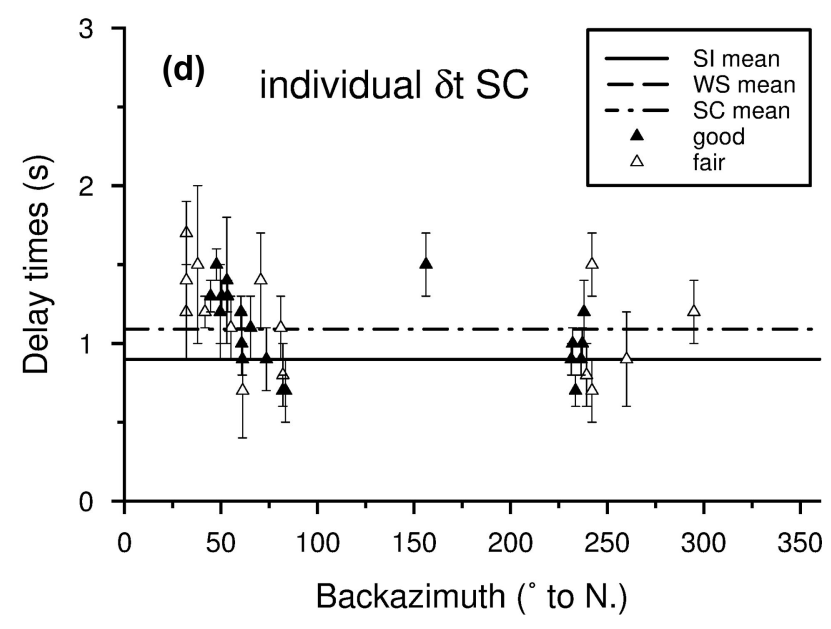

Figure 4. Comparison of the results obtained at station FR.ATE with (a) SI approach (Chevrot 2000), (b) WS stacking approach and the individual splitting measurements as a function of the backazimuth $(\phi$ (c) and $\delta t$ (d) from SC method; Silver \& Chan (1991)). In panels (c) and (d), solid and open triangles account for 'good' and 'fair' splitting measurements, respectively; solid, dashed and dotted dashed lines represent average SI, WS and SC splitting parameters, respectively. For SI: $\phi=-74^{\circ} \pm 1 ; \delta t=0.9 \pm 0.1 \mathrm{~s}$. For WS: $\phi=-78^{\circ} \pm 1 ; \delta t=0.9 \pm 0.1 \mathrm{~s}$. Weighted mean for SC: $\phi=-67^{\circ} \pm 2 ; \delta t=0.8 \pm 0.1 \mathrm{~s}$. SI errors bars represent the standard deviation of splitting intensity computed in each bin. SC errors bars are obtained from the 95 per cent confidence area of the individual energy maps of the transverse component. These results are obtained with 50 events.

deployed in the western and central parts of the belt. This direction is close to the strike of the Pyrenees. Interestingly, no variation of the fast directions can be detected when crossing the SPFT or the NPF. Delay times are relatively high $(\sim 1 \mathrm{~s}$ in average $)$ and display important variations only along the strike of the Pyrenees. We detect the largest $\delta t$ in the Basque country, to the west, and along the Mediterranean coast, to the east ( $>1 \mathrm{~s}$, Fig. $7 \mathrm{~b})$. On the other hand, the central part of the belt, and particularly the eastern part of the Axial Zone, presents the lowest values $(0.6 \mathrm{~s}<\delta t<0.9 \mathrm{~s})$. One should note, however, that the blue patch observed in Fig. 7(b) is produced by only two stations at the border of this zone, with no station in its centre.

Important changes in the splitting pattern occur north of the Pyrenees, in the Aquitaine Basin. Indeed, at a latitude of approximately $43.5^{\circ} \mathrm{N}$, fast directions rotate from $\mathrm{N} 100^{\circ} \mathrm{E}$ to close to $\mathrm{N} 60^{\circ} \mathrm{E}$ (Figs 6 and 7a). Fig. 7(a) shows that most stations in the Aquitaine Basin present fast directions that strongly differ from those observed in the Pyrenean domain, Iberia or Massif Central (blue patch on Fig. 7a).
The change is particularly dramatic along the easternmost transect (stations PE01 to PE22 and PF01 to PF15) between stations PF05 and PF07 which are separated by only $15 \mathrm{~km}$. On the other hand, this transition is less clear on the two other transects. Along the westernmost transect (stations PW01 to PW29), in particular, we observe no significant change in the splitting parameters. However we were not able to obtain measurement at 9 of the 10 northernmost stations of this transect (see Supporting Information Table S2) where the transition likely occurs. Indeed, station PY15, localized $20 \mathrm{~km}$ north of PW01, presents an $\mathrm{N} 60^{\circ} \mathrm{E}$ fast polarization direction. While no significant change in $\phi$ occurs along the central transect (stations PC01 to PC28), delay times slightly decrease north of the NPFT, and then sharply drop north of latitude $43.5^{\circ} \mathrm{N}$. Surprisingly, the fast directions observed at the northernmost stations of this transect are in disagreement with the only station (AUC) previously analysed in the Aquitaine Basin by Barruol \& Souriau (1995). This station which showed a $\mathrm{N} 46^{\circ} \mathrm{E}$ fast direction and a delay time of $1.2 \mathrm{~s}$ was however obtained from a single 'poorly constrained' splitting 


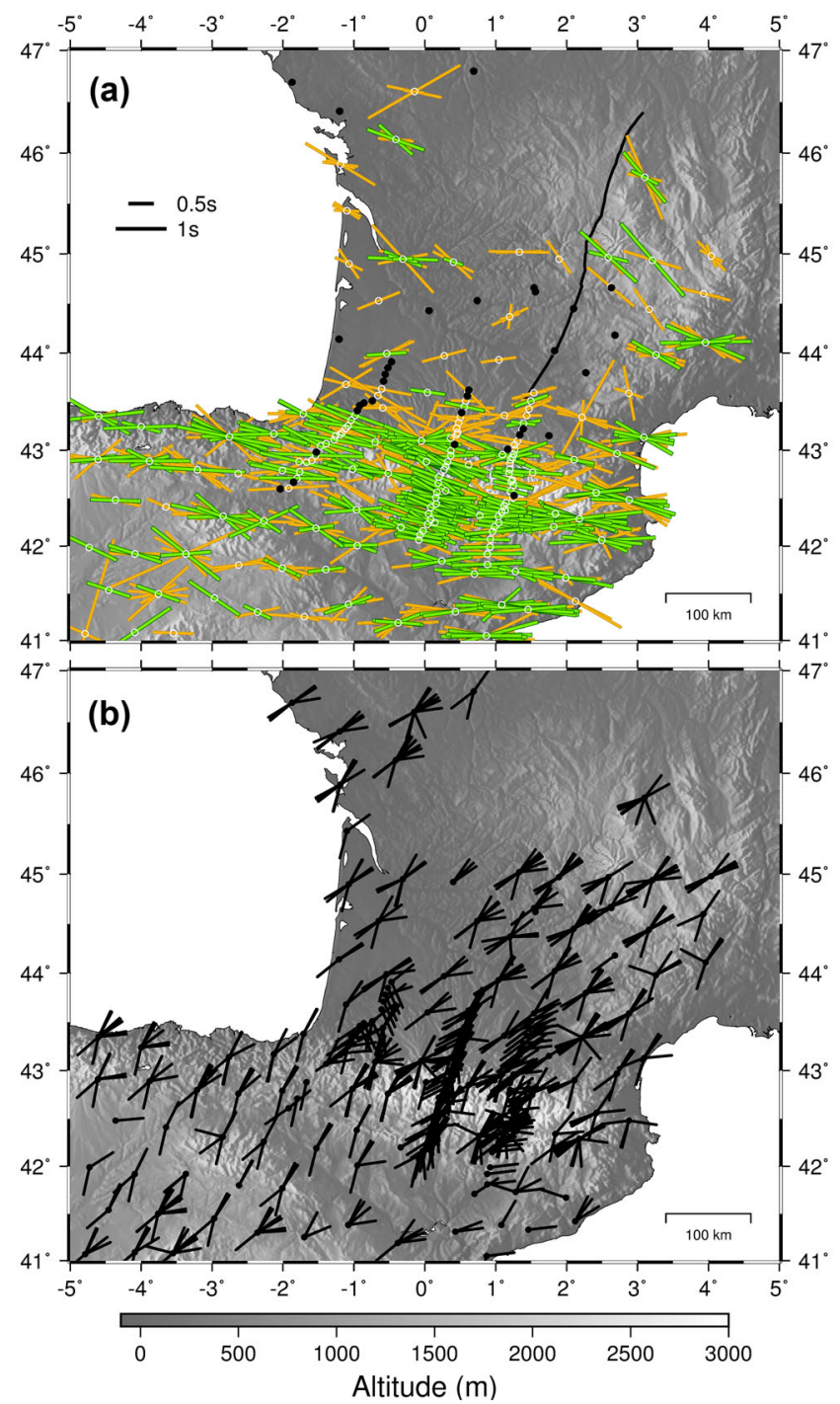

Figure 5. Map presenting the individual splitting measurements at analysed stations. (a) Individual splitting parameters with $\phi$ directions parallel to the bars and $\delta t$ proportional to the length of the bars; green bars account for the 'good' splitting measurement while orange ones account for the 'fair' splitting measurements - 'poor' are not presented nor discussed. Circles indicate the position of the analysed stations; open white circles indicate stations with at least one non-null measurements; solid circles indicate stations where we do not obtain any 'good' or 'fair' splitting measurements. (b) Backazimuth of the events that were estimated as 'good' and 'fair' nulls.

measurement (Barruol \& Souriau 1995). From Fig. 7(b), it is also clear that shear wave splitting in the Aquitaine Basin is characterized by relatively small delay times (typically between $0.4 \mathrm{~s}<\delta t<0.6 \mathrm{~s}$ ) with even nulls observed in the vicinity of the Sillon Houiller ( $\mathrm{SH}$ hereafter). In the NW Aquitaine Basin, however, fast directions rotate back to close to $\mathrm{N} 100^{\circ} \mathrm{E}$ and delay times rise up to $\sim 1 \mathrm{~s}$, that is, close to the values observed in Iberia or along the Pyrenees.

To the east of the network, in the Massif Central, splitting parameters present a quite coherent pattern. Fast directions tend to rotate from the North to the South from $\mathrm{N}-45^{\circ} \mathrm{E}$ to $\mathrm{N}-70^{\circ} \mathrm{E}$, as evidenced by the colour gradient in Fig. 7(a). Delay times range between 0.6 and $1.0 \mathrm{~s}$, with no clear $\mathrm{N}-\mathrm{S}$ variations of their intensity. This shear wave splitting pattern is relatively consistent with results by Barruol \& Granet (2002, purple bars on Fig. 6). Station $\mathrm{CFF}$, to the North, has a fast direction at a high angle from the fast

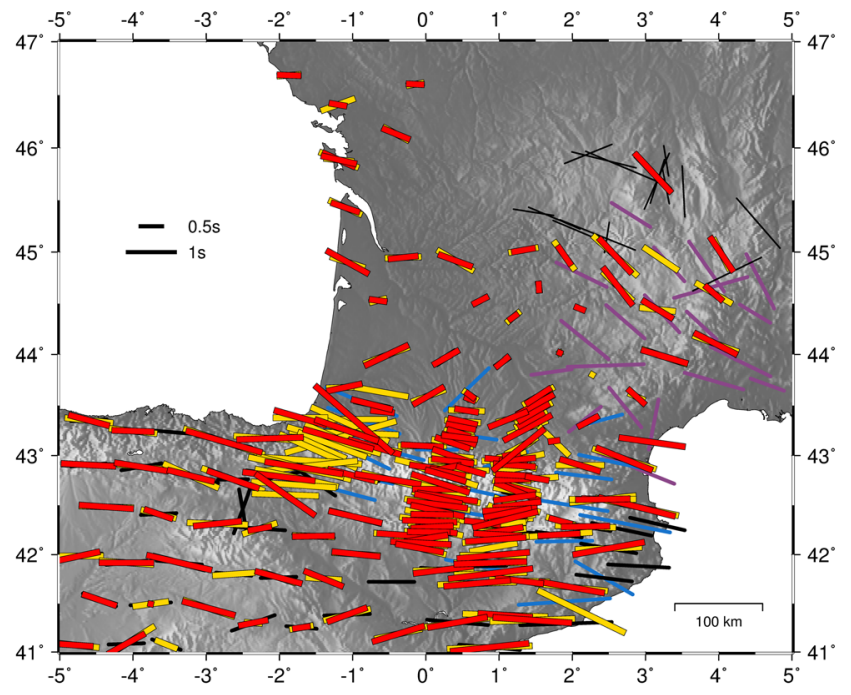

Figure 6. Map of apparent splitting parameters in the Pyrenean domain. Red: averaging performed with SI method (this study); gold: averaging performed with WS technique (this study); blue: measurements from Barruol et al. (1998); thin black: measurements from Babuška et al. (2002); purple: measurements from Barruol \& Granet (2002) and Barruol et al. (2004); thick black: measurements from Díaz et al. (1998) and Díaz et al. (2015).

polarizations directions of Babuška et al. (2002, thin black bars on Fig. 6). Note that all Babuška et al. (2002) splitting parameters and some of the Barruol \& Granet (2002) come from a single event.

\section{DISCUSSION}

\subsection{On the use of single- and multi-events shear wave splitting analysis techniques}

The main input of this study comes from shear wave splitting measurements obtained with different analysis methods to constrain anisotropy beneath the Pyrenean domain. This is obviously not the first attempt to combine different techniques (Long \& van der Hilst 2005; Bonnin et al. 2012; Rasendra et al. 2014; Kong et al. 2015, for the most recent ones), but it is the first time it is performed on such a large data set.

Classical 'single-event' techniques (e.g. Bowman \& Ando 1987; Silver \& Chan 1991), allow us to measure splitting parameters on individual traces and thus to characterize their azimuthal variation which can indicate the presence of layered anisotropy (e.g. Savage \& Silver 1993) or of a dipping symmetry axis (e.g. Babuška et al. 1993). In such cases, more detailed investigations can then be performed to retrieve two-layer models of anisotropy (Silver \& Savage 1994) or the angle of dipping of the symmetry axis (e.g. Š́lený \& Plomerová 1996; Hartog \& Schwartz 2000). If the hypothesis of a single anisotropy layer with horizontal symmetry axes is approximately valid, arithmetic averaging of 'individual' splitting parameters can lead to biased estimates, especially concerning $\phi$ angles. In that case, it is more appropriate to compute average splitting parameters with multi-events approaches. The WS stacking technique is straightforward to perform from SC analysis, as it stacks the 'nulls' and 'non-nulls' individual energy maps to find a global minimum that corresponds to the average $\phi$ and $\delta t$. Bonnin et al. (2012) showed from a synthetic experiment that SI and WS give the same average splitting parameters in the case of a single layer with horizontal symmetry axis but that significant differences can be observed in the case of complex anisotropic structures at depth. 


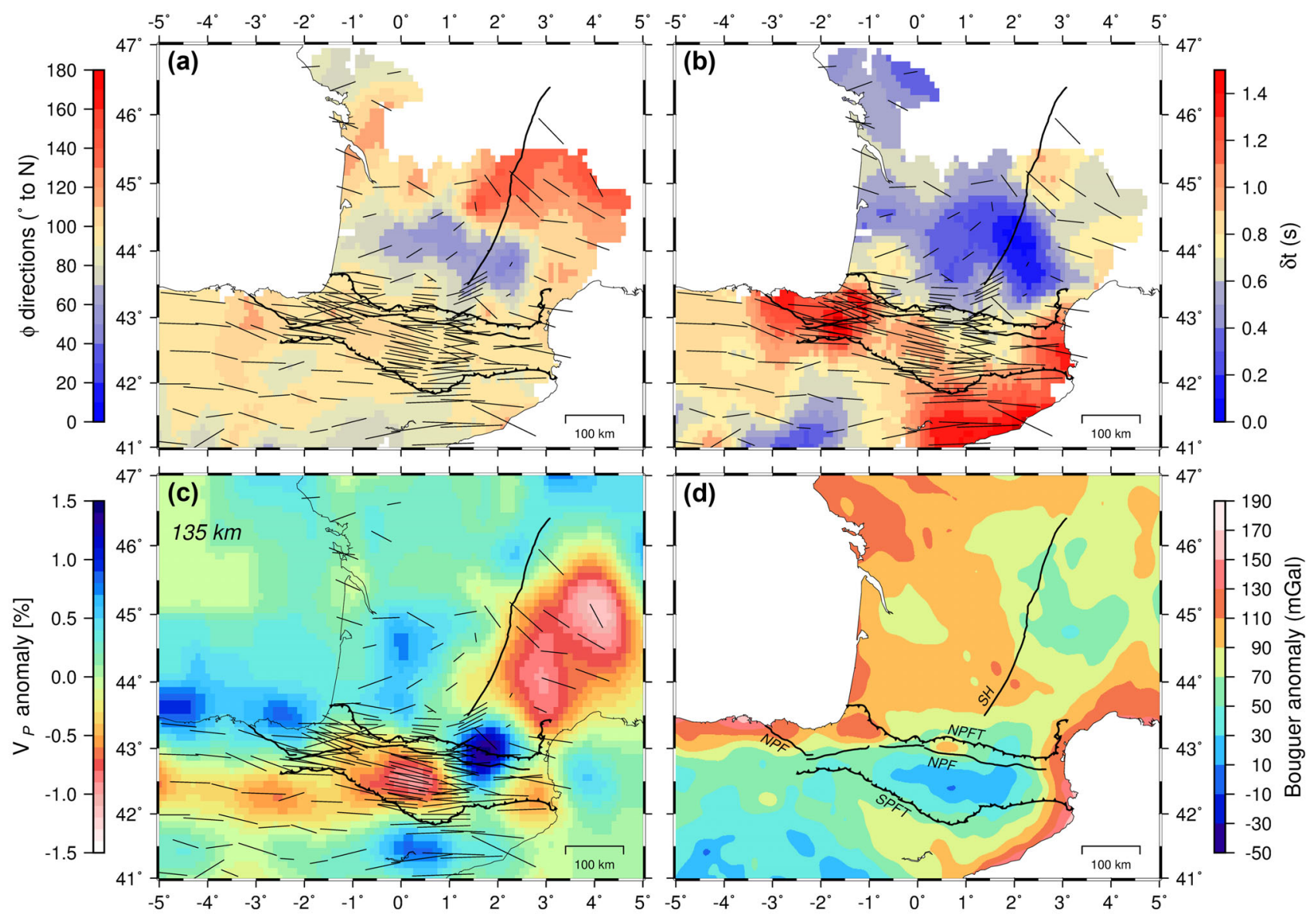

Figure 7. (a) Spatial variations of $\phi$ ( $\phi$ interpolated on a $0.2 \times 0.2$ degree grid). (b) spatial variations of $\delta t(\delta t$ interpolated on a $0.2 \times 0.2$ degree grid). (c) $P$-wave tomographic model of Chevrot et al. (2014) at $135 \mathrm{~km}$ depth. (d) Bouguer anomaly in the Pyrenean domain (from WGM2012, Bonvalot et al. 2012; Bonvalot 2012). Black bars represent splitting parameters of Fig. 6. Thick black lines represent the main discontinuities (NPF, NPFT, SPFT and SH) presented on Fig. 1.

As a consequence, a correspondence of SI and WS results should give us a good confidence in the presence of simple anisotropic structure beneath the station.

As shown in Fig. 6, we generally obtain good to excellent agreement between the average splitting parameters from SI and WS methods. This strongly suggests the absence of widespread complexities in the structure of anisotropy beneath the network and validates our choice to focus on the average splitting parameters. The average splitting parameters obtained in this study are also generally coherent with the previous shear wave splitting measurements in the region (Barruol et al. 1998; Barruol \& Granet 2002; Díaz et al. 2015, blue, purple and thick black bars, respectively, on Fig. 6). This demonstrates the robustness of the splitting parameters obtained in the region and the reproducibility of the results from three different analysis techniques.

\subsection{Sources of the observed seismic anisotropy}

We wish to show now that the abrupt variations of splitting parameters, in some regions, and the presence of coherent directions of fast polarization despite complex lithospheric structures, in others, suggest that two main sources of anisotropy are required to fully explain our results: (1) the lithosphere, for the Aquitaine basin and, to some extent, for the Pyrenees; (2) the asthenosphere, in Iberia, in the Massif Central and also in the Pyrenees.
We will present the arguments for such inferences by comparing finite strain pattern expected from the different geodynamical events that affected the Pyrenean domain with observed average splitting parameters.

\subsubsection{Hercynian orogeny}

Hercynian orogeny ( $\sim 300 \mathrm{Ma})$, deeply affected the lithosphere of present-day Iberia and western Europe (Matte 1991). This major tectonic event has produced crystallographic fabrics in the uppermost mantle and generated crustal to lithospheric scale discontinuities that led to the individualization of lithospheric blocks. In zones that were relatively preserved from more recent tectonic reworking, we can thus expect that the lithosphere has preserved the imprints of this event. Within the Pyrenean domain, Iberia (to the south of the SPFT) and the Aquitaine basin are such zones.

In Iberia, Hercynian deformation caused the development of a NW/SE direction of extension that can still be observed at the surface (Matte 1991, 2001). This direction is, however, at high angle from average $\phi$ measured (close to E/W, Fig. 6 and Díaz et al. 2015). Seismic anisotropy thus cannot be satisfactorily explained by 'frozen-in' Hercynian anisotropy preserved in the uppermost mantle of Iberia. This leads us, as previously suggested by Díaz et al. (2015), to localize seismic anisotropy at larger depths, in the asthenosphere, and thus to discard Hercynian orogeny as the dominant origin of the present day anisotropy. It is however noteworthy 
that Díaz et al. (2015) detect local deviations from this coherent pattern (e.g. Galicia-Tras-os-Montes zone) and that an azimuthal dependence of the splitting parameters is occasionally observed. This suggests a contribution of anisotropy in the Iberian lithosphere. In any case, upper-mantle xenoliths in central Spain show that the lithospheric mantle in this part of Iberia is anisotropic (Puelles et al. 2016).

The abrupt change observed in the shear wave splitting pattern, just northwards of the NPFT in the Aquitaine Basin (Figs 6 and 7) points, on the other hand, to a dominant contribution of the lithosphere. In the eastern part of the basin, the NE/SW fast directions (Fig. 6) are relatively consistent with the Hercynian foliations observed in the Montagne Noire (southernmost Massif Central, e.g. Nicolas et al. 1977). To the north-west, however, Hercynian lineations are parallel to the southern Armorican shear zones oriented NW/SE (e.g. Matte 2001) and are thus not consistent with our observations (close to E/W fast directions, Fig. 6). Finally, because of the thick Mesozoic and Cenozoic sedimentary cover, we have little information on the directions of lineation in the central Aquitaine Basin. We thus cannot rule out the possibility that NE/SW Hercynian lineations, which could explain our observations, exist in this part of the basin.

The SH, which has been shown to separate lithospheric blocks with different seismic anisotropy (Granet et al. 1998; Babuška et al. 2002) and seismic velocities (Chevrot et al. 2014, Fig. 7c), could nevertheless provide some information on the Hercynian flow directions in the lithosphere. In the vicinity of large strike-slip faults in orogenic context one can expect the lithospheric lineations to orient close to parallel to the strike of the fault, as observed for instance in the Himalaya (McNamara et al. 1994). From Figs 7(a)(c) we do see that fast directions in the Aquitaine Basin slightly rotate from the West to the East and tend to orient parallel to the strike of the SH. This could suggest that $\phi$ in this region represents preserved Hercynian flow directions. It is also striking that not only the directions of $\phi$ change along the Aquitaine Basin but the delay times decrease. This decrease is particularly dramatic in the vicinity of the SH (see Fig. 7b). The 'nulls' observed in this zone are however only apparent, as surface waves tomographies show that Aquitanian upper-mantle is anisotropic (Zhu et al. 2015; Nita et al. 2016). Some vertical or lateral complex anisotropy structures thus probably affect the average splitting parameters causing the small to null $\delta t$ as, (i) the presence of strongly dipping anisotropy symmetry axis (Babuška et al. 1993) in the lithosphere west of the SH, as evidenced in the northern Massif Central $\left(60^{\circ}\right.$ from the horizontal, Babuška et al. 2002), (ii) the sampling by $S K S$-waves on both sides of the SH of two lithospheric blocks with significantly different seismic anisotropy characteristics (Babuška et al. 2002), or (iii) the presence of two anisotropy layers (one in the lithosphere, the other in the asthenosphere) with orthogonal symmetry axes. The formers should however be associated with backazimuthal dependence of the splitting parameters, which is not clearly observed. On the other hand, the latter require sufficiently large delay times (probably $>1 \mathrm{~s}$ ) in the lithosphere to 'erase' the W-NW/E-SE fast directions inferred in the asthenosphere from surface waves (Zhu et al. 2015; Nita et al. 2016). This is possible but unlikely given the information we have from the surrounding regions.

\subsubsection{Ib/Eu relative motion before collision}

The opening of the North Atlantic ocean and of the Bay of Biscay during the Early Cretaceous is a key geodynamic event in the Pyre- nean domain. Three competing scenarios/models were proposed to describe the relative motion of Iberia with respect to Eurasia during that period (Barnett-Moore et al. 2016). In a first scenario $\left(\mathrm{M}_{1}\right)$, Iberia moved close to $300 \mathrm{~km}$ along a left-lateral strike-slip shear-zone (the North Pyrenean Fault) with respect to Europe from Aptian to Campanian (Le Pichon \& Sibuet 1971; Choukroune \& Mattauer 1978; Olivet 1996). The inverted Cretacous basins observed along the Pyrenees (Mauléon and Saint-Gaudens basins for instance) were interpreted as pull-apart basins (Choukroune \& Mattauer 1978). In a second scenario $\left(\mathrm{M}_{2}\right)$ derived from the fit of the M0 magnetic anomaly between Iberia and Newfoundland, Iberia is separated from Eurasia at M0 time by a 300-400 km wide Neo-Tethys oceanic basin that was later closed by the 'scissorlike' opening of the Bay of Biscay (Srivastava et al. 1990, 2000; Sibuet et al. 2004; Vissers \& Meijer 2012). This scenario predicts a subduction of an oceanic domain beneath Eurasia, and explains the Cretaceous basins by backarc extension on the Eurasian plate (Sibuet et al. 2004) or slab detachment (Vissers \& Meijer 2012). The last scenario ( $\mathrm{M}_{3}$, Jammes et al. 2009) proposes that most of the eastward $\mathrm{Ib} / \mathrm{Eu}$ motion was accommodated by extension between Newfoundland and Iberian margins from Late Jurassic to Early Cretaceous. This motion caused transtensional deformation in the Pyrenean domain and was followed by an N/S stretching between Iberia and Eurasia-generating the Cretaceous basins observed in the belt - and later by collision during the opening of the Bay of Biscay. Given that the Pyrenees orogeny and opening of the western Mediterranean basin followed these events, it is likely that fabrics acquired during that period were later erased. Discriminating between those models from the interpretation of seismic anisotropy is thus challenging.

The consistency of average $\phi$ along the Pyrenees is in good agreement with $\mathrm{M}_{1}$ (Barruol et al. 1998). This model predicts fast directions oriented along the strike of the NPF. Strike-slip plate boundaries are indeed expected to generate olivine crystallographic fabrics that are strongly anisotropic for vertically propagating shear waves (Tommasi et al. 1999). This geodynamical context is however not necessarily sufficient to explain alone the lateral extent of present-day seismic anisotropy beneath the Pyrenees. Shear wave splitting observations at active strike-slip plate boundaries show that this pattern can be relatively narrow $(50 \mathrm{~km}$ maximum on both sides of the San Andreas fault branches, Bonnin et al. 2010) or even not observed at all (across the North Anatolian fault, for instance, Sandvol et al. 2003; Biryol et al. 2010; Paul et al. 2014). In addition this model would also predict a strongest anisotropy along the NPF, which is not observed.

It is more difficult to define the anisotropy pattern predicted by $\mathrm{M}_{2}$. If a Neo-Tethys oceanic domain did subduct beneath Eurasia, the width of the trench should have been quite limited (a few hundred kilometres maximum). In that case complex toroidal and poloidal mantle flow should have occurred (Funiciello et al. 2006). The fast directions associated to this flow strongly depend on the geometry and the kinematics of the system (e.g. Faccenda \& Capitanio 2013). Moreover, the slab detachment proposed in this model at the closure of the oceanic domain, should then have destroyed the mantle fabrics that would have developed when subduction was active. The relatively simple seismic anisotropy pattern observed beneath the Pyrenees is thus difficult to reconcile with this scenario.

In scenarios $M_{1}$ and $M_{2}$, the Pyrenees should be predominantly cylindrical, that is, with predominantly homogeneous structures along the belt. It is however clear from Fig. 7(b) and from seismic tomography (Chevrot et al. 2014, Fig. 7c) that the Pyrenees are 
rather characterized by along strike structural heterogeneities. This division of the belt in several lithospheric 'domains' is, interestingly, relatively consistent with $\mathrm{M}_{3}$. In that scenario, transform faults that are close to perpendicular to the strike of the belt accommodate the strike-slip component of the $\mathrm{Ib} / \mathrm{Eu}$ motion and individualize lithospheric blocks. These faults could correspond to reactivated Hercynian structures and one of these faults could have been the $\mathrm{SH}$ (Jammes et al. 2009). The slight variations of $\delta t$ along the Pyrenees, which occur along NE/SW boundaries, could mark the presence of these lithospheric blocks, inherited from the opening of the Bay of Biscay. On the other hand, the $\mathrm{N} 100^{\circ} \mathrm{E}$ directions of polarization observed along the Pyrenees, are not in agreement with the N/S to $\mathrm{NE} / \mathrm{SW}$ directions of extension expected from $\mathrm{M}_{3}$. Note that these directions could nevertheless be consistent with average $\phi$ in the Aquitaine Basin.

\subsubsection{Pyrenean orogeny}

The Pyrenean collision, which spread over Campanian to Eocene, impacted terrains spatially limited between the southern and northern Pyrenean Frontal Thrusts. The dynamics of mountain building is known to cause anisotropy to orient along the strike of the belt (Vauchez \& Nicolas 1991) and can thus well explain the fast polarization directions observed along the Pyrenees (Barruol et al. 1998). The development of a pervasive deformation from the surface down to the asthenospheric mantle in that context, can also partly explain the slightly higher $\delta t$ measured in some parts of the Pyrenean range (Fig. 7b) in comparison to surrounding regions. In addition, the Pyrenean collision was the first tectonic event since the Hercynian orogeny able to produce a coherent anisotropy in the NPZ and the PAZ.

Vauchez \& Barruol (1996) and Barruol et al. (1998) however noted that this process efficiently generates anisotropy only in the most central part of a belt and cannot a priori account for seismic anisotropy in its near foreland (beneath PAZ and SPFT for instance). They consequently proposed that seismic anisotropy off the Pyrenean axis originates from inherited Hercynian fabrics.

In light of shear wave splitting results in Iberia (this study and Díaz et al. 2015) which show consistent fast polarization directions across a vast region, we however suggest that anisotropy south of the axial zone is better explained by deformation localized at asthenospheric depths, in relation with the most recent tectonic history of the region.

\subsubsection{Recent geodynamical events}

Hercynian orogeny, Ib/Eu relative motion from Early to Late Cretaceous and Pyrenean collision cannot fully account for the observed seismic anisotropy in the entire Pyrenean domain. In particular, it cannot explain the consistency of average $\phi$ throughout Iberia and the Pyrenees and seismic anisotropy beneath the Massif Central.

Based on shear wave splitting measurements from Morocco (Díaz et al. 2010) to central (Díaz \& Gallart 2014) and northern Spain, Díaz et al. (2015) noted that the coherent fast directions observed in the North then rotate, in the South, around a fast $P$-wave anomaly observed beneath the Alborán basin (Bezada et al. 2013; Bonnin et al. 2014). They conclude that seismic anisotropy in Iberia can be explained by a global asthenospheric flow moving to the NE (Conrad \& Behn 2010) that is deviated by the presence of a lithospheric slab beneath the Alborán Sea. This flow can locally be explained by the Cenozoic and present-day geodynamics of the Mediterranean domain (Faccenna \& Becker 2010; Faccenna et al. 2014).
The climax of the Pyrenean orogeny during Late Eocene was followed, at the Oligocene, by a dramatic change in the tectonic of western Europe (Faccenna et al. 2014). At that period (from 35 to $5 \mathrm{Ma}$ ) the roll-back of the Tyrrhenian slab caused the opening of the Algero-Provençal oceanic basin and, in the last million years, the opening of the Tyrrhenian Sea (Faccenna et al. 2014). At the same time, in the eastern Mediterranean domain, the roll-back of the Hellenic slab caused the extreme stretching of the European continental lithosphere and led to the opening of the Aegean Sea (Faccenna et al. 2014). Shear wave splitting analysis in the Aegean domain (Hatzfeld et al. 2001; Paul et al. 2014) and in Anatolia (Sandvol et al. 2003; Biryol et al. 2010; Paul et al. 2014) evidenced that fast polarization directions are consistent throughout this region and globally point toward the Hellenic trench. Biryol et al. (2010) and Paul et al. (2014) proposed that, despite the important distance to the trench, the coherent NE/SW trending $\phi$ - that is not consistent with surface geology - is related to the asthenospheric flow associated to the roll-back of the Hellenic trench.

It is thus reasonable to consider that a similar process-the roll-back of the Tyrrhenian slab-led to the same consequencesan asthenospheric mantle flow over several hundred kilometres. Barruol \& Granet (2002) and Barruol et al. (2004) previously invoked the asthenospheric flow associated to the Tyrrhenian slab roll-back as a possible source of seismic anisotropy beneath the Massif Central and the French Riviera. This scenario efficiently accounts for the N/S rotation of fast directions (Fig. 6) in the Massif Central (Barruol \& Granet 2002) and along the western Alps (Barruol et al. 2004, 2011), and for the migration to the south of a part of the Massif Central Cenozoic volcanism (Barruol \& Granet 2002). To the west, in the southern Pyrenean domain, this large-scale asthenospheric flow could explain the large-scale coherence of fast directions. It can also explain why the relatively constant delay times in central Iberia tend to increase along the Mediterranean coast (Fig. 7b), where the lithosphere is the thinnest (Fig. 7d). Azimuthal anisotropy inferred from surface waves in the asthenospheric mantle of western Europe and western Mediterranean basin (Zhu et al. 2015; Nita et al. 2016), with fast directions coherent from central Iberia to the Corsica-Sardinia block, supports this assumption. If seismic anisotropy in Iberia originates from the deformation caused by the opening of the western Mediterranean basin, it could also explain why average $\phi$ remains constant across the Pyrenees.

As this event is relatively recent and was not followed by any thermal or tectonic event, and considering the fact that the absolute velocities of the lithospheres are low in the region (Gripp \& Gordon 2002), it is likely that the asthenospheric mantle preserved the imprint of this event. Faccenna \& Becker (2010) and Faccenna et al. (2014) furthermore show that although they are now quite spatially limited, lithospheric slabs in western Mediterranean (in particular the Calabrian slab) still control the upper-mantle flows in the region. As directions of flow in the upper-mantle did not significantly change since $5 \mathrm{Ma}$ it can also explain why seismic anisotropy generated by the opening of the western Mediterranean basin could have been preserved until today.

\subsection{Summary}

We argue that two dominant sources of anisotropy are required to fully explain the seismic anisotropy pattern of the Pyrenean domain:

(i) A spatially coherent asthenospheric flow related to the recent geodynamics of the western Mediterranean that can account for the 
homogeneity of $\phi$ throughout Iberia, the Pyrenees and southeastern France.

(ii) Lithospheric fabrics that can explain the sharp lateral variations of splitting parameters in the Aquitaine basin and to some extent along the Pyrenees. In the Aquitaine Basin seismic anisotropy is probably inherited from the Hercynian orogeny, while the apparent partitioning of the Pyrenees likely results from the Mesozoic evolution of the $\mathrm{Ib} / \mathrm{Eu}$ relative motions.

A striking feature of the Pyrenean domain however remains that seismic anisotropy beneath the southern Aquitaine Basin (below $\mathrm{N} 45^{\circ} \mathrm{N}$ ) is significantly different from what is observed in the surrounding regions. This raises the issue of the origin of this specificity. In particular, if northern Iberia, Massif Central and the Pyrenees were affected by the asthenospheric flow, why not the Aquitaine Basin? A possible solution is to invoke the presence of two layers of anisotropy: an Hercynian lithospheric fabric interfering with the 'regional' asthenospheric flow with perpendicular symmetry axes. This could notably explain the observed decrease in the delay times (Fig. 7b). However, we were not able to fully investigate this possibility due to the relatively short operating time of the stations installed in the basin.

The extent of the French permanent broad-band network in the Aquitaine Basin in the following years should provide further constraints on seismic anisotropy in that region.

\section{CONCLUSIONS}

We analysed with different methods shear wave splitting beneath 203 temporary and permanent broad-band stations in France and Spain. The combined PyrOPE and IberArray experiments allow us to present a shear wave splitting map that covers the entire Pyrenees including its southern and northern forelands and that evidences two seismic anisotropy patterns in that region. Different hypothesis have been proposed in the past to explain the seismic anisotropy pattern beneath the Pyrenean domain: (1) vertically coherent deformation from the surface to the asthenosphere during the Alpine orogeny and (2) global-scale asthenospheric mantle flow. Our results, which encompass the Aquitaine Basin and the Massif Central, suggest that both sources are required to fully explain the seismic anisotropy pattern.

The consistency of fast directions throughout most parts of the study region (Iberia, Pyrenees, Massif Central) can be explained by asthenospheric flow associated with the retreat of the Tyrrhenian slab in the last 35 Myr. This is in good agreement with the geodynamic models of the western Mediterranen and with fast directions of azimuthal anisotropy beneath the Liguro- and Algero-Provençal basins.

Beneath the Aquitaine Basin, the origin of seismic anisotropy remains unclear. Splitting parameters are clearly different from those in northern Iberia, Pyrenees and Massif Central and seem to be related to the transition between Iberian and European lithospheres north of the NPZ. Seismic anisotropy beneath the Aquitaine Basin probably results from the contribution of both frozen-in Hercynian fabrics in the lithosphere and asthenospheric flow.

\section{ACKNOWLEDGEMENTS}

We thank the two anonymous reviewers and the editors Juan Carlos Afonso and Sylvia Hales that greatly helped improve the quality of the manuscript. The PYROPE experiment was supported by the French Research Agency ANR blanc program (project PYROPE,
ANR-09-BLAN-0229) (Chevrot \& Sylvander 2017). We also acknowledge SISMOB, the French seismic mobile pool and RESIF, for providing us with the seismological instrumentation for the temporary and permanent deployments. We also thank the IGN and IGCC for making their broad-band data available to us. IberArray is a contribution of the Team Consolider-Ingenio 2010 TOPO-IBERIA (CSD2006-00041) (Institute Earth Sciences 'Jaume Almera' CSIC (ICTJA Spain) 2007). We thank the BGI (http://bgi.obs-mip.fr) for providing us with the Bouguer anomaly data. All figures except Figs 2 and 3 were produced by the GMT graphic software (Wessel \& Smith 1998; Wessel et al. 2013). Seismological data have been partly requested and preprocessed using the ObsPy library (Krischer et al. 2015).

\section{REFER E N CES}

Babuška, V., Plomerová, J. \& Š́lený, J., 1993. Models of seismic anisotropy in the deep continental lithosphere, Phys. Earth planet. Inter., 78(3-4), 167-191.

Babuška, V., Plomerová, J., Vecsey, L., Granet, M. \& Achauer, U., 2002. Seismic anisotropy of the French Massif Central and predisposition of Cenozoic rifting and volcanism by Variscan suture hidden in the mantle lithosphere, Tectonics, 21(4), 11-1-11-20.

Barnett-Moore, N., Hosseinpour, M. \& Maus, S., 2016. Assessing discrepancies between previous plate kinematic models of Mesozoic Iberia and their constraints, Tectonics, 35(8), 1843-1862.

Barruol, G. \& Granet, M., 2002. A Tertiary asthenospheric flow beneath the southern French Massif Central indicated by upper mantle seismic anisotropy and related to the west Mediterranean extension, Earth planet. Sci. Lett., 202(1), 31-47.

Barruol, G. \& Mainprice, D., 1993. A quantative evaluation of the contribution of crustal rocks to the shear-wave splitting of teleseismic SKS waves, Phys. Earth planet. Inter., 78(3-4), 281-300.

Barruol, G. \& Souriau, A., 1995. Anisotropy beneath the Pyrenees range from teleseismic shear wave splitting: results from a test experiment, Geophys. Res. Lett., 22(4), 493-496.

Barruol, G., Souriau, A., Vauchez, A., Díaz, J., Gallart, J., Tubía, J.M. \& Cuevas, J., 1998. Lithospheric anisotropy beneath the Pyrenees from shear wave splitting, J. geophys. Res., 103(B12), 30 039-30 053.

Barruol, G., Deschamps, A. \& Coutant, O., 2004. Mapping upper mantle anisotropy beneath SE France by SKS splitting indicates Neogene asthenospheric flow induced by Apeninic slab roll-back and deflected by the Alpine roots, Tectonophysics, 394, 125-138.

Barruol, G., Bonnin, M., Pedersen, H., Bokelmann, G.H.R. \& Tiberi, C., 2011. Belt-parallel mantle flow beneath a halted continental collision: the Western Alps, Earth planet. Sci. Lett., 302(3-4), 429-438.

Bezada, M.J., Humphreys, E.D., Toomey, D.R., Harnafi, M., Dávila, J.M. \& Gallart, J., 2013. Evidence for slab rollback in westernmost Mediterranean from improved upper mantle imaging, Earth planet. Sci. Lett., 368, 51-60.

Biryol, C.B., Zandt, G., Beck, S.L., Özacar, A.A., Adiyaman, H.E. \& Gans, C.R., 2010. Shear wave splitting along a nascent plate boundary: the North Anatolian Fault Zone, Geophys. J. Int., 181(3), 1201-1213.

Bonnin, M., Barruol, G. \& Bokelmann, G.H.R., 2010. Upper mantle deformation beneath the North American-Pacific plate boundary in California from SKS splitting, J. geophys. Res., 115(B4), B04306, doi:10.1029/2009JB006438.

Bonnin, M., Tommasi, A., Hassani, R., Chevrot, S., Wookey, J. \& Barruol, G., 2012. Numerical modelling of the upper-mantle anisotropy beneath a migrating strike-slip plate boundary: the San Andreas Fault system, Geophys. J. Int., 191(2), 436-458.

Bonnin, M., Nolet, G., Villaseñor, A., Gallart, J. \& Thomas, C., 2014. Multiple-frequency tomography of the upper mantle beneath the African/Iberian collision zone, Geophys. J. Int., 198(3), 1458-1473.

Bonvalot, S., 2012. The international gravimetric bureau, in The Geodesist's Handbook 2012, vol. 86 of Journal of Geodesy, pp. 787-974, doi:10.1007/s00190-012-0584-1. 
Bonvalot, S. et al., 2012. World Gravity Map, 1:50000000 map.

Bowman, J.R. \& Ando, M., 1987. Shear-wave splitting in the upper-mantle wedge above the Tonga subduction zone, Geophys. J. R. astr. Soc., 88(1), $25-41$.

Chevrot, S., 2000. Multichannel analysis of shear wave splitting, J. geophys. Res., 105(B9), 21 579-21 590.

Chevrot, S. \& Sylvander, M., 2017. Seismic network X7: PYROPE PYRenean Observational Portable Experiment (RESIF-SISMOB), RESIF - Réseau sismologique et géodésique français. URL: https://doi.org/10.15778/RESIF.X72010, doi:10.15778/RESIF.X72010.

Chevrot, S., Favier, N. \& Komatitsch, D., 2004. Shear wave splitting in three-dimensional anisotropic media, Geophys. J. Int., 159(2), 711-720.

Chevrot, S. et al., 2014. High-resolution imaging of the Pyrenees and Massif Central from the data of the PYROPE and IBERARRAY portable array deployments, J. geophys. Res., 119(8), 6399-6420.

Choukroune, P., 1992. Tectonic evolution of the Pyrenees, Annu. Rev. Earth Planet. Sci., 20, 143-158.

Choukroune, P. \& Mattauer, M., 1978. Tectonique des plaques et Pyrénées : sur le fonctionnement de la faille tranformante nord-pyrénéenne ; comparaisons avec des modèles actuels, Bull. Soc. Géol. Fr., 20(5), 689700

Conrad, C.P. \& Behn, M.D., 2010. Constraints on lithosphere net rotation and asthenospheric viscosity from global mantle flow models and seismic anisotropy, Geochem. Geophys. Geosyst., 11(5), doi:10.1029/2009GC002970.

Crampin, S., 1984. An introduction to wave propagation in anisotropic media, Geophys. J. R. astr. Soc., 76(1), 17-28.

Díaz, J. \& Gallart, J., 2014. Seismic anisotropy from the Variscan core of the Iberia to the Western African Craton: new contrains on upper mantle flow at regional scales, Earth planet. Sci. Lett., 394, 48-57.

Díaz, J., Gallart, J., Hirn, A. \& Paulssen, H., 1998. Anisotropy beneath the Iberian Peninsula: the contribution of the ILIHA-NARS broad-band experiment, Pure appl. Geophys., 151(2), 395-405.

Díaz, J. et al., 2010. Mantle dynamics beneath the Gibraltar Arc (western Mediterranean) from shear-wave splitting measurements on a dense seismic array, Geophys. Res. Lett., 37(18), L18304. doi:10.1029/2010GL044201.

Díaz, J. et al., 2015. From the Bay of Biscay to the High Atlas: completing the anisotropic characterization of the upper mantle beneath the westernmost Mediterranean region, Tectonophysics, 663, 192-202.

Dziewoński, A.M. \& Anderson, D.L., 1981. Preliminary reference Earth model, Phys. Earth planet. Inter., 25(4), 297-356.

Efron, B. \& Tibshirani, R., 1991. Statistical data analysis in the computer age, Science, 253(5018), 390-395.

Ekström, G., Nettles, M. \& Dziewoński, A.M., 2012. The global CMT project 2004-2010: Centroid-moment tensors from 13,017 earthquakes, Phys. Earth planet. Inter, 200-201, 1-9.

Faccenda, M. \& Capitanio, F.A., 2013. Seismic anisotropy around subduction zones: Insights from three-dimensional modeling of upper mantle deformation and SKS splitting calculation, Geochem. Geophys. Geosyst., 14(1), 243-262.

Faccenna, C. \& Becker, T.W., 2010. Shaping mobile belts by small-scale convection, Nature, 465(7298), 602-605.

Faccenna, C. et al., 2014. Mantle dynamics in the Mediterranean, Rev. Geophys., 52(3), 283-332.

Funiciello, F., Moroni, M., Piromallo, C., Faccenna, C., Cenedese, A. \& Bui, H.A., 2006. Mapping mantle flow during retreating subduction: laboratory models analyzed by feature tracking, J. geophys. Res., 111(B3), B03402, doi:10.1029/2005JB003792.

Granet, M., Glahn, A. \& Achauer, U., 1998. Anisotropic measurements in the Rhinegraben area and the French Massif Central: geodynamics implications, Pure appl. Geophys., 151(2-4), 333-364.

Gripp, A.E. \& Gordon, R.G., 2002. Young tracks of hotspots and current plate velocities, Geophys. J. Int., 150(2), 321-361.

Hartog, R. \& Schwartz, S.Y., 2000. Subduction-induced strain in the upper mantle east of the Mendocino triple junction, California, J. geophys. Res., 105(B4), 7909-7930.
Hatzfeld, D. et al., 2001. Shear wave anisotropy in the upper mantle beneath the Aegean related to internal deformation, J. geophys. Res., 106(12), $30737-30753$.

Institute Earth Sciences "Jaume Almera" CSIC (ICTJA Spain), 2007. IberArray: International Federation of Digital Seismograph Networks. URL: http://iberarray.ictja.csic.es/, doi:10.7914/SN/IB

Jammes, S., Manatschal, G., Lavier, L. \& Masini, E., 2009. Tectonosedimentary evolution related to extreme crustal thinning ahead of propagating ocean: example of the western Pyrenees, Tectonics, 28(4), TC4012, doi:10.1029/2008TC002406.

Kennett, B.L.N. \& Engdahl, E.R., 1991. Traveltimes for global earthquake location and phase identification, Geophys. J. Int., 105(2), 429-465.

Kong, F., Gao, S.S. \& Liu, K.H., 2015. A systematic comparison of the transverse energy minimization and splitting intensity techniques for measuring shear-wave splitting parameters, Bull. seism. Soc. Am., 105(1), 230-239.

Krischer, L., Megies, T., Barsch, R., Beyreuther, M., Lecocq, T., Caudron, C. \& Wassermann, J., 2015. ObsPy: a bridge for seismology into the scientific Python ecosystem, Comput. Sci. Discovery, 8, 014003, doi:10.1088/17494699/8/1/014003

Le Pichon, X. \& Sibuet, J.-C., 1971. Western extension of boundary between European and Iberian plates during the Pyrenean orogeny, Earth planet. Sci. Lett., 12(1), 83-88.

Long, M.D. \& van der Hilst, R.D., 2005. Estimating shear-wave splitting parameters from broadband recordings in Japan: a comparison of three methods, Bull. seism. Soc. Am., 95(4), 1346-1358.

Mainprice, D. \& Silver, P.G., 1993. Interpretation of SKS-waves using samples from the subcontinental lithosphere, Phys. Earth planet. Inter., 78(34), 257-280.

Mainprice, D., Barruol, G. \& Ben Ismaill, W., 2000. The seismic anisotropy of the Earth's mantle: from single crystal to polycrystal, in Earth's Deep Interior: Mineral Physics and Tomography from the Atomic to the Global Scale, vol. 117, pp. 237-264, AGU, doi:10.1029/GM117p0237.

Matte, Ph., 1991. Accretionary history and crustal evolution of the Variscan belt in Western Europe, Tectonophysics, 196, 309-337.

Matte, Ph., 2001. The Variscan collage and orogeny (480-290 Ma) and the tectonic definition of the Armorica microplate: A review, Terra Nova, 13(2), 122-128

McNamara, D.E., Owens, T.J., Silver, P.G. \& Wu, F.T., 1994. Shear wave anisotropy beneath the Tibetan plateau, J. geophys. Res., 99(B7), 13 65513665 .

Monteiller, V. \& Chevrot, S., 2010. How to make robust splitting measurements for single-station analysis and three-dimensional imaging of seismic anisotropy, Geophys. J. Int., 182(1), 311-328.

Nicolas, A. \& Christensen, N.I., 1987. Formation of anisotropy in the upper mantle peridotites: a review, Geodyn. Ser., 16, 111-123.

Nicolas, A., Bouchez, J.-L., Blaise, J. \& Poirier, J.-P., 1977. Geological aspects of deformation in continental shear zones, Tectonophysics, 42(1), $55-73$.

Nita, B., Maurya, S. \& Montagner, J.-P., 2016. Anisotropic tomography of the European lithospheric structure from surface wave studies, Geochem. Geophys. Geosyst., 17(6), 2015-2033.

Olivet, J.L., 1996. La cinématique de la plaque Ibérique, Bulletin des Centres de Recherches Exploration-Production Elf-aquitaine, 20, 131-195.

Paul, A., Karabulut, H., Mutlu, A.K. \& Salaün, G., 2014. A comprehensive and densely sampled map of shear-wave azimuthal anisotropy in the Aegean-Anatolia region, Earth planet. Sci. Lett., 389, 14-22.

Puelles, P., Ábalos, B., Gil Ibarguchi, J.I., Sarrionandia, F., Carracedo, M. \& Fernández-Armas, S., 2016. Petrofabric and seismic properties of lithospheric mantle xenoliths from the Calatrava volcanic field (Central Spain), Tectonophysics, 683, 200-215.

Rasendra, N., Bonnin, M., Mazzotti, S. \& Tiberi, C., 2014. Crustal and upper mantle anisotropy related to fossilized transpression fabric along the Denali Fault, northern Canadian Cordillera, Bull. seism. Soc. Am., 104(4), 1964-1975

Restivo, A. \& Helffrich, G., 1999. Teleseismic shear wave splitting measurements in noisy environments, Geophys. J. Int., 137(3), $821-830$. 
Sandvol, E., Turkelli, N., Zor, E., Gok, R., Bekler, T., Gurbuz, C., Seber, D. \& Barazangi, M., 2003. Shear wave splitting in a young continent-continent collision: an example from Eastern Turkey, Geophys. Res. Lett., 30(24), 8041, doi:10.1029/2003GL017390.

Savage, M.K., 1999. Seismic anisotropy and mantle deformation: what have we learned from shear wave splitting?, Rev. Geophys., 37(1), 65-106.

Savage, M.K. \& Silver, P.G., 1993. Mantle deformation and tectonics: constraints from seismic anisotropy in the western United States, Phys. Earth planet. Inter., 78(3-4), 207-227.

Sibuet, J.-C., Srivastava, S.P. \& Spakman, W., 2004. Pyrenean orogeny and plate kinematics, J. geophys. Res., 109, B08104, doi:10.1029/2003JB002514.

Š́lený, J. \& Plomerová, J., 1996. Inversion of shear-wave splitting parameters to retrieve three-dimensional orientation of anisotropy in continental lithosphere, Phys. Earth planet. Inter., 95(3-4), 277-292.

Silver, P.G. \& Chan, W.W., 1991. Shear wave splitting and subcontinental mantle deformation, J. geophys. Res., 96(B10), 16 429-16 454.

Silver, P.G. \& Savage, M.K., 1994. The interpretation of shear-wave splitting parameters in the presence of two anisotropic layers, Geophys. J. Int., 119(3), 949-963.

Srivastava, S.P., Schouten, H., Roest, W.R., Klitgord, K.D., Kovacs, L.C., Verhoef, J. \& Macnab, R., 1990. Iberian plate kinematics: a jumping plate boundary between Eurasia and Africa, Nature, 344(6268), 756-759.

Srivastava, S.P., Sibuet, J.-C., Cande, S., Roest, W.R. \& Reid, I.D., 2000. Magnetic evidence for slow seafloor spreading during the formation of the Newfoundland and Iberian margins, Earth planet. Sci. Lett., 182(1), $61-76$.

Tommasi, A., Tikoff, B. \& Vauchez, A., 1999. Upper mantle tectonics: threedimensional deformation, olivine crystallographic fabrics and seismic properties, Earth planet. Sci. Lett., 168(1-2), 173-186.

Vauchez, A. \& Barruol, G., 1996. Shear-wave splitting in the Appalachians and Pyrenees: importance of the inherited tectonic fabric of the lithosphere, Phys. Earth planet. Inter., 95(3-4), 127-138.

Vauchez, A. \& Nicolas, A., 1991. Mountain building: strike-parallel motion and mantle anisotropy, Tectonophysics, 185(3-4), 183-201.

Vissers, R.L.M., 1992. Variscan extension in the Pyrenees, Tectonics, 11(6), 1369-1384.

Vissers, R.L.M. \& Meijer, P.T., 2012. Iberian plate kinematics and Alpine collision in the Pyrenees, Earth-Sci. Rev., 114(1-2), 61-83.

Wessel, P. \& Smith, W.H.F., 1998. New, improved version of generic mapping tools released, EOS, Trans. Am. geophys. Un., 79(47), 579, doi:10.1029/98EO00426.

Wessel, P., Smith, W. H.F., Scharroo, R., Luis, J. \& Wobbe, F., 2013. Generic mapping tools: improved version released, EOS, Trans. Am. geophys. Un., 94(45), 409-410.

Wolfe, C.J. \& Silver, P.G., 1998. Seismic anisotropy of oceanic uppermantle: shear wave splitting methodologies and observations, J. geophys. Res., 103(B1), 749-771.
Wüstefeld, A. \& Bokelmann, G.H.R., 2007. Null detection in shear-wave splitting measurements, Bull. seism. Soc. Am., 97(4), 1204-1211.

Wüstefeld, A., Bokelmann, G.H.R., Zaroli, C. \& Barruol, G., 2008. SplitLab: a shear-wave splitting environnement in Matlab, Comput. Geosci., 34(5), 515-528.

Zhu, H., Bozdağ, E. \& Tromp, J., 2015. Seismic structure of the European upper mantle based on adjoint tomography, Geophys. J. Int., 201(1), 1852.

\section{SUPPORTING INFORMATION}

Supplementary data are available at $G J I$ online.

Figure S1. Detail of the three PYROPE transects with the name of all the stations.

Figure S2. Stereographic projections of the 'good' and 'fair' splitting measurements performed at each station. Each individual $S K S$ splitting measurement is projected along its backazimuth and inclination, the orientation of each segment representing the azimuth $\phi$ and the length of the bar the delay time $\delta t$. The inner circle represents an inclination of $5^{\circ}$, the dashed circle an inclination of $10^{\circ}$ and the external circle an inclination of $15^{\circ}$. On the first page are only the permanent stations (CA, FR and RD networks); on the other ones all the temporary stations (IB and X7 networks).

Table S1. Information on the data set analysed at each station. Net.: network code; Station: station code; $\varphi$ : latitude of the station; $\theta$ : longitude of the station; Time range: operating period of the station; $\#_{f}$ : number of events downloaded; $\#_{m}$ : number of measurements.

Table S2. Apparent and average splitting parameters by stations. Net: network code; Sta: station code; $\varphi$ : latitude; $\theta$ : longitude; $\phi$ : apparent fast polarization; $\delta t$ : apparent delay time; $\#_{b}:$ number of bins used for the multichannel analysis; g: number of 'good' nonnull measurements; f: number of 'fair' non-null measurements; $n$ : number of 'nulls'. SI: results from multichannel analysis (Chevrot 2000); WS: results from the Wolfe \& Silver (1998) stacking approach; Mean SC: arithmetic mean of non-nulls single-events from Silver \& Chan (1991) method.

Please note: Oxford University Press is not responsible for the content or functionality of any supporting materials supplied by the authors. Any queries (other than missing material) should be directed to the corresponding author for the paper. 